Funding: See page 215

Peer review: This article has been subject to a double blind peer review process

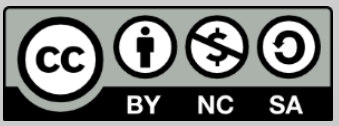

(c) Copyright: The Authors. This article is issued under the terms of the Creative Commons Attribution NonCommercial Share Alike License, which permits use and redistribution of the work provided that the original author and source are credited, the work is not used for commercial purposes and that any derivative works are made available under the same license terms.

\section{Training Future Actors in the Food System: a new collaborative cross-institutional, interdisciplinary training programme for students}

\author{
Kelly Reed*1, Rosemary Collier ${ }^{1}$, Rebecca White ${ }^{2}$, Rebecca \\ Wells ${ }^{3}$, John Ingram², Rosina Borelli², Barbara Haesler ${ }^{4}$, \\ Martin Caraher ${ }^{3}$, Tim Lang ${ }^{3}$, Alex Arnall ${ }^{5}$, Raquel Ajates \\ Gonzalez ${ }^{3}$, Harley Pope ${ }^{5}$, Lauren Blake ${ }^{4}$, Roger Sykes ${ }^{2}$ \\ ${ }^{1}$ University of Warwick, ${ }^{2}$ University of Oxford, ${ }^{3}$ City University of London, \\ ${ }^{4} \mathrm{LCIRAH},{ }^{5}$ University of Reading \\ *Correspondence: ifstal-warwick@warwick.ac.uk
}

\begin{abstract}
There is an urgent need to train a cohort of professionals who can address and resolve the increasing number of fundamental failings in the global food system. The solutions to these systemic failings go far beyond the production of food, and are embedded within broad political, economic, business, social, cultural and environmental contexts. The challenge of developing efficient, socially acceptable and sustainable food systems that meet the demands of a growing global population can only be tackled through an interdisciplinary systems approach that integrates social, economic and environmental dimensions. The new crossinstitutional training programme, IFSTAL (Innovative Food Systems Teaching and Learning), is designed to improve post-graduate level knowledge and understanding of food systems from a much broader interdisciplinary perspective, which can be applied to students' own studies. Ultimately, these graduates should be equipped to apply critical interdisciplinary systems thinking in the workplace to understand how problems are connected, their root causes and where critical leverage points might be. This article outlines the programme and presents a review of its first year (2015-2016 academic year).
\end{abstract}

Keywords: Food security, Systems thinking, Virtual learning environment, Pedagogy 


\section{Introduction}

Although a sufficient amount of food is produced currently to feed the world's population, problems of uneven distribution, poor access and high levels of waste along the supply chain mean that hunger remains an everyday challenge for almost 795 million people worldwide (FAO 2015). In addition, non-communicable diseases, related to poor diet and obesity, are also on the rise (World Bank 2011; Tanumhardjo et al. 2007). This failure to address a basic human need will only intensify with further challenges from an increasing population (around 9 billion by 2050), climate change, economic fluctuations and changes in consumption patterns linked to urbanisation and increased prosperity (Smith 2001; Tilman and Clark 2015; Grafton et al. 2015).

It is generally recognised that ensuring global food security, and therefore alleviating food insecurity, is a multidimensional problem (FAO 2016). There is no one-size-fits-all solution. Interventions must be tailored to local conditions, including the availability of, and access to, food, utilisation of food products based on cultural and dietary requirements, and provision of long-term stability (FAO 1996; Jones et al. 2013). Thus, approaches to tackling food insecurity need to be appropriate and comprehensive, with the necessary political commitment to securing success. Building sustainable food systems has become a key global priority, with the aim of redirecting our policies and activities towards improved diet, societal welfare and environmental sustainability (GPAFSN 2016).

What do we mean by food systems? Although many definitions and models exist, here we describe the food system as including all activities, resources and actors engaged in the production, processing, transportation, consumption and disposal of food (Ericksen 2008; Ingram 2009; Ericksen et al. 2010; Ingram 2011). A food system operates within, and is influenced by, social, political, economic and environmental contexts; for example, the governance and economics of food production; its sustainability; how food affects health and well-being, including nutrition, obesity and food safety; and how food production affects the natural environment. All of this is also strongly influenced by global drivers, such as population growth and climate change. Food systems are therefore complex and adaptive, meaning that the whole system is greater than the sum of its parts, with high levels of interaction at a range of levels along different temporal, spatial and institutional scales. The interconnected and dynamic nature of the food system allows outcomes to be achieved via many possible pathways, and to be influenced by many factors, but also means that unanticipated outcomes and unintended consequences may occur. In order to better work with 
and manage the interconnected nature of the food system, a more holistic way of thinking and working is needed to provide an understanding of how problems are connected, their root causes, and where critical leverage points might be.

The concept of a food system is not new, but few models exist that go beyond one disciplinary perspective or one section of the system (Sobal et al. 1998; Ingram 2011). Individual disciplines tend to conceptualise the food system from their own perspective; however from a multidisciplinary point of view, there are many different food systems and this should be taken into account when trying to address global food challenges. It has been suggested that systems thinking methodologies can help to stimulate discussion on options for change across the full range of food system activities (i.e. from production to consumption), as well as providing a framework for systematic analysis of interactions and trade-offs, balanced across a range of societal goals (Ingram and

Brklacich 2002; Ericksen 2008; Ingram 2009; Ingram 2011). Identifying and modelling the fundamental properties of the food system could help to ensure that its essential outcomes are maintained or enhanced over time and across generations.

This should be led by 'food system thinkers' who work in inter- and transdisciplinary ways, and requires individuals and groups to design new ways of communicating and working together. While an increasing number of graduate programmes on food security and related topics exist in England, no English higher education institution (HEI) delivers a 'food system approach' combining the essential aspects of food system activities and their outcomes for food security and the environment; socioeconomic and environmental drivers; and policy and governance. Furthermore, no university has the range of expertise necessary to equip the cohort of food systems professionals who are needed so urgently.

The current challenge is to train a cohort of graduate students to think and act beyond traditionally narrow, field specific understandings of long-term food security issues and instead embrace more systemic approaches. This means not just understanding the methods, soft skills and networks needed to make an effective 'food systems thinker', but also being able to apply these approaches to practical interventions to solve global food issues. Thus, in order to provide the training needed to create a generation of 'food systems thinkers', the Innovative Food Systems Teaching and Learning (IFSTAL) programme was created. 


\section{IFSTAL: A new collaborative food systems training programme}

IFSTAL is an interactive cross-institutional training programme designed to improve post-graduate level knowledge and understanding of food systems from different perspectives. By participating in IFSTAL students, each focusing on a relatively narrow topic within their own discipline, gain a much broader perspective of the food system, which they can apply to their own studies and subsequently within the context of the workplace. Ultimately, these graduates should be equipped to apply critical, interdisciplinary systems thinking in the workplace to address issues of long-term food security.

IFSTAL is funded to run for three years by the Higher Education Funding Council for England (HEFCE) Catalyst Fund, starting in October 2015. The programme is delivered through a strategic collaboration between HEls with complementary research specialisms, food systems skills, research specialisms and professional networks, giving students access to academics with very diverse interests and expertise. The Higher Education Institutes (HEI) collaborating in IFSTAL are the University of Oxford; City, University of London; the Leverhulme Centre for Integrative Research on Agriculture and Health (LCIRAH) - a consortium comprising the Royal Veterinary College, the London School of Hygiene and Tropical Medicine and the School of Oriental and African Studies; the University

Table 1: Example areas of expertise related to the food system within the IFSTAL consortium.

\begin{tabular}{ll}
\hline $\begin{array}{l}\text { Areas of expertise related to the food } \\
\text { system }\end{array}$ & Consortium members \\
\hline $\begin{array}{l}\text { Crop science, agriculture, horticulture and } \\
\text { animal science }\end{array}$ & $\begin{array}{l}\text { Oxford; Reading; } \\
\text { Warwick; LCIRAH }\end{array}$ \\
$\begin{array}{l}\text { Environmental change and food systems } \\
\text { Food and agricultural economics and } \\
\text { statistics }\end{array}$ & Oxford; Reading \\
$\begin{array}{l}\text { Food policy, food regimes analysis, and } \\
\text { regulatory issues }\end{array}$ & City; Warwick \\
$\begin{array}{l}\text { Food system actors, governance and } \\
\text { consumption patterns }\end{array}$ & Warwick; City; Oxford; \\
$\begin{array}{l}\text { Nutrition, diets, food safety and health } \\
\text { studies }\end{array}$ & LCIRAH \\
$\begin{array}{l}\text { Technical and economic studies of food Oxford; Reading } \\
\text { chains }\end{array}$ & Reading; LCIRAH \\
\hline
\end{tabular}


of Reading; and the University of Warwick. Table 1 shows the consortium members and their areas of expertise. The IFSTAL consortium provides training to students through a unique collaborative cross-institutional programme focusing on the high-level skills needed to understand, analyse, tackle and communicate the complex, interdisciplinary and systems-based problems facing the food sector.

The programme is voluntary and is available to all post-graduate students from any discipline at the participating HEls. All face-to-face lectures and events are conducted outside of the students' core course hours. The IFSTAL programme carries no credits, but a certificate of participation can be requested at the end of the year.

IFSTAL is also unique in that it bridges the gap between the worlds of study and work. The programme emphasises the development of transferable skills, uses frameworks based on the workplace, works on real-world challenges and creates opportunities for students to meet and work alongside people operating within the food system.

The objectives of IFSTAL are to:

1. Establish a pioneering consortium of universities to deliver collaborative training and capacity building in the holistic study of food systems.

2. Develop, implement and assess a new mode of teaching based on inter-university collaboration and exploiting the latest learning technologies.

3. Enhance student learning, insights, experiences and opportunities by offering a range of topics to set their specialist areas of study within a full food systems/food security context.

4. Create a cohort of Masters and PhD graduates equipped to address food systems challenges by combining a deep understanding of their specialism with critical and innovative thinking of the broader social, economic and environmental context.

\section{Benefits to students}

IFSTAL is designed to augment an individual's post-graduate studies with theory, knowledge, skills and values that are aligned with the challenges faced by the food system today. Figure 1 shows the IFSTAL student skills framework and the components of the IFSTAL programme. Students have the opportunity to collaborate with students from the different HEls, allowing, for example, sociologists to discuss food issues with nutritionists or veterinary students with engineers (Ajates Gonzalez and Wells 2016). In addition, the programme aims to increase employment 
prospects by allowing students to engage with a range of food sector practitioners and by providing students with opportunities for dissertation placements and internships.
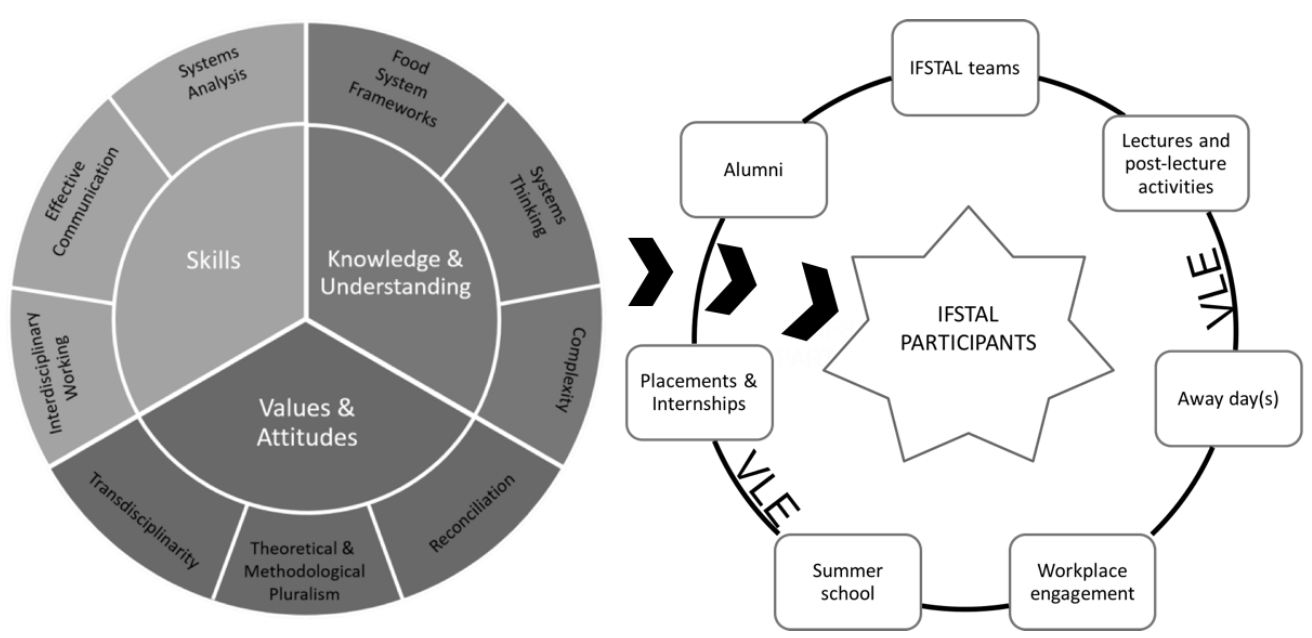

Fig. 1. The IFSTAL student skills framework (to the left) and a representation of the different components of the IFSTAL programme, including the virtual learning environment (VLE) (to the right).

\section{Benefits to the workplace}

Organisations linked to IFSTAL gain from interaction with a pool of highly motivated students who are potential employees with systems thinking skills. They have the opportunity to offer research placements and the potential to provide input from the workplace to the development of future workforce members.

\section{Programme Design and Implementation 2015/2016}

Each consortium member employs an education coordinator (EC) to implement the programme locally, and the ECs work collaboratively on all aspects of the IFSTAL programme. The team includes a lead academic at each partner institution, a programme manager and a workplace lead. Figure 1 highlights the interconnected nature of the different parts of the programme which ensures that IFSTAL works effectively. Delivery of the IFSTAL programme started in October 2015, and in its first year the programme offered an on-line virtual learning environment (VLE), a series of eight live lectures delivered during Terms 1 and 2, an Away Day, and a Summer School. 
To address workplace skills, there were two workshops with representatives from industry, NGOs and charities. These workshops focused on the 'hard' and 'soft' skills that are essential in the workplace. This, together with an emphasis on the development of 'food systems thinking skills', became the foundation of the IFSTAL programme.

The programme is supported by an Advisory Board comprising senior representatives from stakeholder and student representatives, partner institutions and education innovators. The Board meets twice a year to review progress and make recommendations for future development of the programme.

\section{The virtual learning environment}

The Royal Veterinary College (RVC) developed a bespoke IFSTAL VLE using the e-learning platform Moodle. The system allows enrolled postgraduate students to login using their local log-in details, via their own university Moodle site (or Blackboard in the case of Reading University), which is linked to the IFSTAL VLE. This became available at the end of September 2015. Figure 2 shows a screenshot of the IFSTAL VLE.

At its core, Moodle is educational software grounded in a philosophy of collaborative learning, often referred to as social constructionist pedagogy (Al-Ajlan and Zedan 2008). Using Moodle terminology, the IFTSAL team created 'courses' linked to each of the eight lectures delivered during Terms 1 and 2, each with its own set of resources and activities, including audio and video material. Each Moodle course consisted of 'lessons', including reading materials, activities (such as quizzes) and forum discussions that encouraged participation between students. The chat function was also used in Term 2 to facilitate a Q\&A session between the students and Professor Tim Lang (City, University of London). The 'Choice module', which creates a poll, was used to question students, for example, in Term 2 students were asked to indicate the companies that particularly interested them for internships and future employment. Students were informed about IFSTAL events and activities through a fortnightly news digest to all registered students via the VLE. 


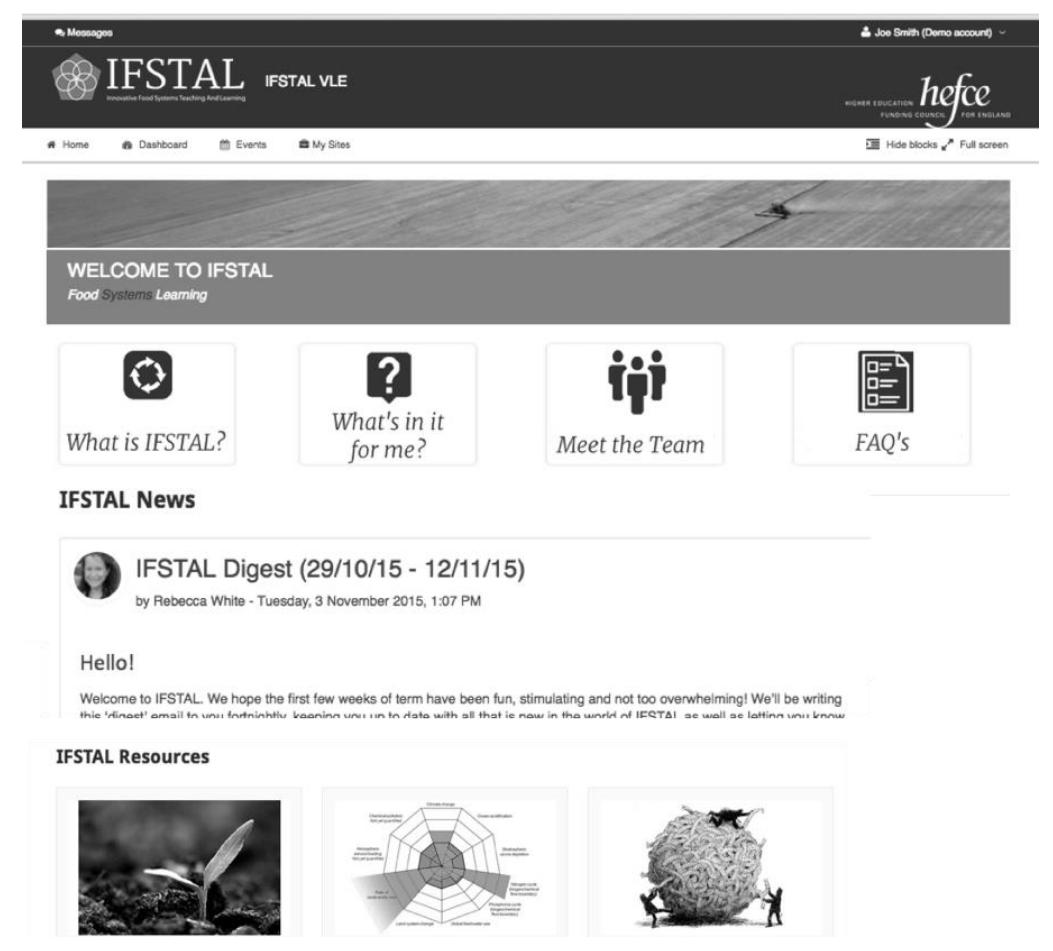

Fig. 2. Screen shot of the IFSTAL virtual learning environment.

\section{Lecture series}

IFSTAL ran eight lectures during 2015/16, four during Term 1 and four during Term 2 and were designed to present key themes in the food system as well as systems thinking methods. After each lecture there was a workshop to consolidate learning from the lecture, as well as to provide networking opportunities.

Delivery of the lectures was rotated between institutions and live streamed to each partner location, as well as on the VLE for those unable to attend in person. The lectures used several technologies. For example, to facilitate cross-institutional interaction during the lectures, questions were posed via Twitter and via a discussion forum on the VLE. Alternatively, when Adobe Connect was used to deliver lectures, questions were posed via the Adobe Connect chat function. Furthermore, live polling technology was used for lectures 3 and 4 . These technologies have allowed all members of the different institutions, including distance learners, to feel part of the whole IFSTAL community and contribute to discussions.

\section{Away Day}

During Term 2, 30 students from across the participating HEls attended an Away Day at the University of Oxford. Participating students were able 
to develop their communication skills with the help of an expert facilitator, present their research to a mixed and friendly audience, meet and network with fellow students and food sector professionals, and practice their systems thinking skills. The students worked on case studies based on real-world systems challenges and five speakers from different sectors shared their thoughts about, and experiences of, working in the food system, as well as providing feedback on student presentations.

\section{Summer School}

The first Summer School was at the University of Reading during the first week of July 2016. The international cohort of 30 students from the partner HEls, representing over 20 nationalities, came from a range of disciplinary backgrounds including law, business, nutrition, agricultural sciences, veterinary medicine, food policy, anthropology, epidemiology and development studies. The Summer School aimed to examine food systems and their issues in more detail, by allowing the students to engage with experts in systems thinking, food policy and other aspects of the food system and develop skills necessary for their career. The students learned about problem solving and communication with experts from academia, government, industry and NGOs. The students also spent one day visiting food producers, processers and retailers, and waste management facilities.

\section{Assessing the success of year 1}

The programme was designed to facilitate on-line as well as face-to-face learning, making IFSTAL accessible to distance learners, as well as those based at participating institutions. One of the success criteria for HEFCE, was to provide a more efficient delivery of food systems education and learning for a greater number of students than could be achieved by HEls operating individually. The levels of on-line participation and attendance at face-to-face events were recorded throughout the year. In addition, impact case studies were assembled, for example, of a student gaining an internship through participation in IFSTAL.

\section{Participation through the VLE}

By the end of October 2015 around 245 students had registered through the VLE. This had increased to over 300 students by January 2016, 
reaching 341 by the end of Term 2 . The numbers for each HEI were Oxford 70, LCIRAH 76, Reading 70, City 73, and Warwick 52.

\section{Attendance at IFSTAL face-to-face events}

The inaugural lecture (delivered at Oxford and live-streamed) was wellattended with over 250 attendees across the four events (Oxford, Warwick, Reading and a joint City University-LCIRAH event in London). For the next three lectures in Term 1 numbers remained relatively stable at around 200 students across all locations. During Term 2 there was a slight decrease in the numbers of students attending events, with an average of around 100 attendees per event across all locations.

There was an application process for both the Away Day and the Summer School, as both events were designed for a maximum of 30 students. The students were required to provide a statement describing how they would benefit from attending. Both events were oversubscribed and a selection process was undertaken to determine who would attend.

\section{Student feedback}

To facilitate enhancement of the programme over time, several feedback sessions were organised at the HEls. Further feedback was collected at the end of the Away Day and Summer School and included questions about the relevance of the material, what the students did or did not enjoy, and their thoughts about the overall structure and content of the events.

In June 2016, at the end of the first year (2015-2016), a questionnaire designed in Survey Monkey was disseminated for students to complete. All student responses were anonymous and a prize draw was included to encourage participation. Sixty students took part in the survey, 11 from City, 6 from LCIRAH, 7 from Oxford, 14 from Reading, 14 from Warwick and 8 whose home institutions were not identified. The questionnaire focused on three areas: the past, for example, how they found out about IFSTAL; the present, for example, what they have found useful or not from the programme; and the future, for example, whether other resources or content would be useful on-line. Generally, the feedback was positive and many of the students found IFSTAL to be a very useful addition to their studies and in helping them think about their future careers. In particular, students stated an appreciation for the blended learning, the on-line resources, the networking opportunities and interaction with the workplace. The feedback was then used to help reflect on and develop further the IFSTAL programme for year 2 . 


\section{Workplace engagement and Internships}

Developing productive relationships with workplace actors is a central part of the IFSTAL offering to students. The collaborating institutions already had a large number of connections and the network is being extended continually. For the students, this element of the programme can provide a pathway to employment or to further study. Whilst it is recognised that some graduates may not go on to work in the food sector, gaining an appreciation of the benefit of a systems approach to addressing complex problems will prepare them for employment in a range of other sectors.

In the first year of the programme, student-workplace interactions consisted of guest lectures, work placements and post-graduation internships with a range of organisations from national and local government, industry and NGO's. These enabled students to interact with practitioners, to form interesting research questions and to apply critical thinking to real world problems. In addition, a small number of organisations provided dissertation placements for Masters students, allowing them to work with the organisation to formulate interesting research questions, which they developed as a critical study on a theme of interest to the workplace. Furthermore, 11 IFSTAL students were successfully placed within internships and many others have gone on to employment within the food sector. However, tracking the successful placement of students has proved challenging, as it requires the students themselves to inform IFSTAL. Therefore, employment and internship metrics are biased towards those students who have informed IFSTAL.

\section{Creating a food thinkers network}

A further aspect of assessing the success of IFSTAL is to maintain links with the masters and PhD students who participate in IFSTAL, but who leave during the three year programme and go on to work or further study. To maintain this link an IFSTAL alumni network was created at the end of Year 1. The purpose of the alumni network is to foster and develop a strong cohort identity, enable students to collaborate with each other during the next stages of their careers, and to build a multisectoral network. This will provide a valuable resource for them to draw on as professionals.

The network of IFSTAL alumni is supported in a number of ways. Examples include, facilitation of professional and academic networking between current students, alumni and research staff; communicating 
with alumni through the website, social media and newsletters; and organising events and activities where alumni can engage with IFSTAL (guest lectures, summer schools, work placements and hosting internships). LinkedIn is one of the tools being used to keep students connected. In particular, the 'groups' function is an increasingly common space for users to gather and exchange ideas and IFSTAL is beginning to utilise this functionality for its alumni.

\section{Reflections on Year 1: Designing Year 2}

Critical discourse is emerging around Massive Open On-line Courses (MOOCs) and the opportunity for institutions to develop more strategic approaches to on-line learning. A MOOC is generally seen as an on-line course aimed at unlimited participation and open access, where traditional course materials such as filmed lectures and readings are supplemented by interactive user forums to support community interactions among students and teachers.

Where IFSTAL is different is that the programme takes a blended or hybrid approach to teaching, integrating face-to-face activities with online materials, creating a flexible and effective model for teaching and learning (Bruff et al. 2013). By utilising on-line content delivery, which can be accessed anytime, the face-to-face session is free for feedback, application and interaction, as well as greater flexibility in teaching style and course content (Aycock et al. 2002; Hill 2012). At the same time the on-line platform allows for interaction between students at the different partner institutions, and helps to consolidate the IFSTAL cohort.

For IFSTAL year 1 the lecture series and activities were linked with on-line material, including lecture recordings, readings, activities and forum discussions. Feedback from the June 2016 survey indicated that $98 \%$ of the students found the on-line lecture recordings useful to very useful, while over $70 \%$ found the online forums, activities, notifications and social media useful to very useful. Over $70 \%$ of students also indicated that the live lectures, post lecture activities, VLE material, Away Day and networking activities helped facilitate their interdisciplinary thinking.

Building on the face-to-face activities of year 1, year 2 was designed to deliver an enhanced range of learning activities including networking, flipped-classrooms, lectures and symposiums. The ECs used research on learning outcomes, constructive alignment, e-learning, active learning and blended learning to help design both the face-to-face activities and to inform the on-line course content (Biggs 2002; Fry et al. 2009; Monk et al. 2011; Parker 2011). The positive experience and feedback received from the students for the Away Day and Summer School, especially with 
regard to networking with the workplace, encouraged a greater number of events for year 2 . Three away days were subsequently planned into the programme for year 2, providing students with greater opportunities to meet workplace representatives and fellow students.

Feedback regarding the VLE, through the face-to-face feedback sessions as well as the June 2016 survey, suggested that students found it difficult at times to navigate the Moodle site and felt they would have benefited from better signposting. This feedback helped to develop the design for the VLE for year 2. This includes a much simpler front page; all on-line course information under one button and presented in smaller chunks; and a greater use of Moodle features, such as the progress button to give students an idea of their progress through each course, how long each course is, as well as a quiz at the end to test their learning.

\section{Working collaboratively across institutions}

Collaboration across the HEls underpins IFSTAL and is one of its innovative features. Once the cross-university working practices, legal arrangements, roles and specialisms had been established the beginning of the project, the core group began to work with a range of departments to deliver the IFSTAL programme. One of the most important early collaborations was between the IT and technology departments. These departments, in each of the HEls, worked together to implement Learning Tools Interoperability $\left(\mathrm{LTI}^{\circledR}\right)$ between the Universities' individual (and different) virtual learning platforms and the IFSTAL Moodle VLE, creating a seamless link for students. The HEIs also had different live streaming technologies and so coordination was required to ensure that live streaming from each location was possible during Terms 1 and 2.

The communication and marketing teams were also instrumental in helping to advertise IFSTAL and provided suggestions about branding. As the pedagogy of IFSTAL developed, there was an education workshop to bring together some of the key educationalists within each HEI. This was influential in helping to consolidate the teaching methods used by IFSTAL, as well as the learning objectives for the programme.

The collaborations across the HEls have not always been easy, especially as institutions and departments within them are generally not structured to support collaborative approaches to learning, research, and organisational functioning (Kezar 2005). Sometimes, finding the right person to approach was a challenge, however, the willingness of each $\mathrm{HEI}$ to collaborate and become involved in the shared vision and goals of IFSTAL made these collaborations possible. The ECs from each institution 
have also benefitted from the expertise at the other institutions, for example, training in student engagement and group learning (Warwick), support and training for Moodle (RVC) and training in systems thinking (Reading). IFSTAL has therefore created a large and effective collaborative network, including a number of different departments and teams within each $\mathrm{HEI}$.

The IFSTAL team has been an integral part of delivering the IFSTAL programme from the start. The collaboration between the diverse range of IFSTAL team members has resulted in producing what may be described as a 'high-performing cooperative group', maximising net benefits for the team (Smith and Imbrie 2007; Goring et al. 2014). The characteristics of the group includes diversity in skills and experience, effective communication, positive interdependence of team members, and individual and group accountability. By establishing processes and goals, as well as understanding and managing the strengths and weaknesses of each team member, the team has managed to work efficiently together. In order to facilitate communication various techniques have been applied, including a weekly skype call for the EC's and Workplace Lead, where they discuss weekly updates and work going forward. The IFSTAL team also meet every three months for a project meeting, where progress and actions going forward are discussed.

\section{Conclusions}

The need to train people in food systems thinking in order to address the increasing number of fundamental systemic failings in the global food system is a critical challenge. In order to train a cohort of graduate students to think and act beyond traditional disciplinary understandings of long-term food security issues and embrace more systemic approaches the Innovative Food Systems Teaching and Learning (IFSTAL) programme was created. This article describes how the programme was established and activities and achievements during the first year of the three-year programme. Whilst it is too early to evaluate the success of the programme in terms of its impact on the workplace it is possible to draw some early conclusions.

For the first year, the IFSTAL team engaged collaboratively to provide students with an interdisciplinary programme that aimed to enhance their systems thinking skills and provide opportunities for collaboration with students from a range of disciplines, as well as different workplace organisations. Over 340 students registered for the IFSTAL programme by the end of year 1 (2015-2016), half of which have now become a part of the IFSTAL alumni network. Feedback from the students about the 
programme was generally very positive, with the blended learning, the on-line resources, networking and opportunities to interact with the workplace being useful additions to their current studies and future careers. As a response to this feedback changes were made to the programme for year 2 (2016/17) to enhance the learning experience, including the creation of four online modules. Improvements are also needed in relation to tracking students beyond their studies and the development of an alumni network aims to help with this. Further monitoring will be implemented in year 2 including an external review of the IFSTAL programme.

The programme highlights the benefits of working collaboratively across institutions to aid multi-disciplinary and trans-disciplinary learning. The technology available, such as Moodle, has facilitated in the creation of an effective cross-institutional multi-disciplinary blended learning programme. Although, the organisational structure of HEls can sometimes be problematic in creating these collaborations, the IFSTAL team has so far overcome these barriers through good team work and communication.

\section{Acknowledgements}

The IFSTAL Programme is funded under the Catalyst Fund from the Higher Education Funding Council for England (HEFCE). It is co-funded by the collaborating institutions both in-kind and in cash. Ethics approval for the on-line survey was given on the 18 May 2016 by the Central University Research Ethics Committee, University of Oxford, reference number SOGE 1A-69.

\section{List of Figures}

Fig. 1. The IFSTAL student skills framework (to the left) and a representation of the different components of the IFSTAL programme (to the right)

Fig. 2. Screen shot of the IFSTAL virtual learning environment

\section{List of Tables}

Table 1. Areas of expertise related to the food system within the IFSTAL consortium 


\section{References}

Ajates Gonzalez, R. and R., Wells (2016), 'Tackling Food Topics', Magazine of the British Sociological Association, Spring 2016, pp. 35

Al-Ajlan, A. and H. Zedan (2008), 'Why Moodle', in Proceedings of the 2008 12th IEEE International Workshop on Future Trends of Distributed Computing Systems, FTDC, 2008, Kunming, China, IEEE, pp. 58-64

Aycock, A., C. Garnham and R. Kaleta (2002), 'Lessons learned from the hybrid course project', Teaching with Technology Today, 8(6)

Biggs, J.B. (2002), Aligning teaching assessment to curriculum objectives. LTSN Imaginative Curriculum website www.Itsn.ac.uk/genericcentre, accessed 20 December 2016

Bruff, D.O., D.H. Fisher, K.E. McEwen and B.E. Smith (2013), 'Wrapping a MOOC: Student Perceptions of an Experiment in Blended Learning', Journal of Online Learning and Teaching, 9 (2), 187-199

Ericksen, P.J. (2008), 'Conceptualizing food systems for global environmental change research', Global Environmental Change, 18, 234245

Ericksen, P.J., B. Stewart, J. Dixon, D. Barling, P. Loring, M. Anderson and J. Ingram (2010), 'The value of a food system approach', in Ingram, J., P. Ericksen and D. Liverman (eds.), Security and global environmental change, London: Earthscan, pp. 25-45

FAO (1996), 'The Rome Declaration on World Food Security and the World Food Summit Plan of Action', website

http://www.fao.org/docrep/003//w3613e/w3613e00.htm accessed 27 March 2017

FAO, IFAD and WFP (2015) The State of Food Insecurity in the World 2015.

Meeting the 2015 international hunger targets: taking stock of uneven progress,

Rome: FAO.Website http://www.fao.org/3/a-i4646e.pdfaccessed 07 April 2017

FAO (2016), The State of Food and Agriculture: Climate Change, Agriculture and Food Security, Rome: FAO

Fry, H., S. Ketteridge and S. Marshall (2008), A handbook for teaching and learning in higher education: Enhancing academic practice, London:

Routledge

Goring S.J., K.C. Weathers, W.K. Dodds, P.A. Soranno, L.C. Sweet, K.S. Cheruvelil, J.S. Kominoski, J. Rüegg, A.M. Thorn and R.M. Utz 
(2014), 'Improving the culture of interdisciplinary collaboration in ecology by expanding measures of success', Frontiers in Ecology and the Environment, 12 (1), 39-47

GPAFSN (2016), Food systems and diets: Facing the challenges of the 21st century. London, UK. Website

https://glopan.org/sites/default/files/ForesightReport.pdf accessed 07 April 2017

Grafton, R.Q., C. Daugbjerg and M.E. Qureshi (2015), 'Towards food security by 2050', Food Security, 7, 179-183

Hill, P. (2012), 'Online educational delivery models: A descriptive view', EDUCAUSE Review, 47 (6), 84-97

Ingram, J.S.I. and M. Brklacich (2002), 'Global Environmental Change and Food Systems (GECAFS). A new, interdisciplinary research project', Die Erde, 113, 427-435

Ingram, J.S.I. (2009), 'Food system concepts', in Rabbinge, R. and A. Linneman (eds.) ESF/COST Forward Look on European Food Systems in a Changing World, European Science Foundation, Strasbourg

Ingram, J.S.I. (2011), 'A food systems approach to researching food security and its interactions with global environmental change', Food Security, 3, 417-431

Jones, A.D., F.M. Ngure., G. Pelto and S.L. Young (2013), 'What are we assessing when we measure food security? A compendium and review of current metrics', Advances in Nutrition, 4 (5), 481-505

Kezar, A. (2005), 'Redesigning for Collaboration within Higher Education Institutions', Research in Higher Education 46 (7), 831-860

Monk, N., C. Chillington Rutter., J. Neelands and J. Heron (2011), Openspace Learning: A Study in Transdisciplinary Pedagog, London:

Bloomsbury Academic

Parker, P. (2011), A Guide to Writing Learning Outcomes for Modules and Programmes,

http://jiscdesignstudio.pbworks.com/f/Learning\%200utcomes\%20paper \%20Pam\%20May11.pdf, accessed 20 December 2016

Smith, K.A. and P.K. Imbrie (2007), Teamwork and project management (3rd edn), New York, NY: McGraw Hill

Smith, V. (2001), Feeding the world: a challenge for the twenty-first century, Boston: MIT Press

Sobal, J., L.K. Khan and C. Bisogni (1998), 'A conceptual model of the food and nutrition system', Social Science \& Medicine 47, 853-863 
Tanumhardjo, S., S. Anderson., M. Kaufer-Horwitz., L. Bode and N.J.

Emenaker (2007), 'Poverty, Obesity, and Malnutrition: An International Perspective Recognizing The Paradox', Journal of the American Dietetic Association 107 (11), 1966-1972

Tilman, D and M. Clark (2015), 'Food, Agriculture \& the Environment: Can We Feed the World \& Save the Earth?', Daedalus 144 (4), 8-23

World Bank (2011) The Growing Danger of Non-Communicable Diseases. Acting Now to Reverse Course. Washington DC: World Bank

\section{To cite this article:}

Reed, K., et al. (2017). Training Future Actors in the Food System: a new collaborative cross-institutional, interdisciplinary training programme for students. Exchanges: The Warwick Research Journal, 4(2), 201-218. Retrieved from:

http://exchanges.warwick.ac.uk/index.php/exchanges/article/view/145 